\title{
\begin{tabular}{l|l} 
Mibraries & DSpace@MIT
\end{tabular}
}

\author{
MIT Open Access Articles
}

\section{Feedback Model of Air Transportation System Change: Implementation Challenges for Aviation Information Systems}

The MIT Faculty has made this article openly available. Please share how this access benefits you. Your story matters.

Citation: Mozdzanowska, A.L., R.E. Weibel, and R.J. Hansman. “Feedback Model of Air Transportation System Change: Implementation Challenges for Aviation Information Systems." Proceedings of the IEEE 96.12 (2008): 1976-1991. (c) Copyright 2010 IEEE

As Published: http://dx.doi.org/10.1109/JPROC.2008.2006118

Publisher: Institute of Electrical and Electronics Engineers

Persistent URL: http://hdl.handle.net/1721.1/58876

Version: Final published version: final published article, as it appeared in a journal, conference proceedings, or other formally published context

Terms of Use: Article is made available in accordance with the publisher's policy and may be subject to US copyright law. Please refer to the publisher's site for terms of use. 


\section{Feedback Model of Air}

\section{Transportation System Change: Implementation Challenges for Aviation Information Systems}

\section{The process of putting new systems into place should maintain system safety, improve performance and minimize conflict between needs of operators, controllers and pilots.}

By Ale ksandra L. Mozdzanowska, Roland E. Weibel, and R. John Hansman, Member IEEE

ABSTRACT | The U.S. air transportation system faces substantial challenges in implementing new aviation information systems to meet future demand. These challenges need to be understood and addressed in order to successfully meet future system needs. This paper uses a feedback model to describe the processes by which system change occurs. In addition, key issues in the dynamics of system change, with particular emphasis on stakeholder cost-benefit dynamics, and safety approval processes are identified. Overcoming stakeholder barriers and ensuring efficient safety approval and certification process are key enablers to the successful implementation of aviation information systems into the air transportation system. The implementation of Automatic Dependent Surveillance-Broadcast and integration of unmanned aircraft systems into the air transportation system are discussed as examples of current technology-dependent system changes.

KEYWORDS | Air transportation; Automatic Dependent Surveillance-Broadcast (ADS-B); cost-benefit; stakeholder; system change; Unmanned Aircraft Systems (UAS)

Manuscript received November 16, 2007; revised August 11, 2008. Current version published January 16, 2009. This work was supported in part by the U.S. Federal Aviation Administration under the Joint University Program, Grant FAA95-G-017, and the National Center of Excellence for Aviation Operations Research under Grant DTFA01-C-00030.

A. L. Mozdzanowska is with the Engineering Systems Division, Massachusetts Institute of Technology, Cambridge, MA 02139 USA (e-mail: alexm@mit.edu).

R. E. Weibel is with the Department of Aeronautics and Astronautics, Massachusetts Institute of Technology, Cambridge, MA 02139 USA (e-mail: weibel@mit.edu). R. J. Hansman is with the Massachusetts Institute of Technology, Cambridge, MA 02139 USA (e-mail: rjhans@mit.edu).

Digital Object Identifier: 10.1109/JPROC.2008.2006118

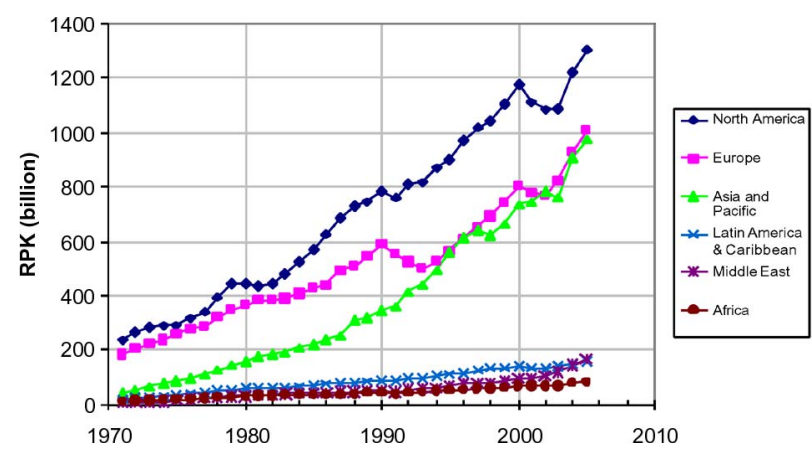

Fig. 1. Growth of passenger traffic.

\section{INTRODUCTION}

The U.S. air transportation system is currently facing a number of challenges - including growth in demand, as shown in Fig. 1; increasing environmental requirements; and emerging vehicle classes such as unmanned aircraft systems (UASs). To meet future demands, system change is required. Aviation information systems are seen as a key component of improving the efficiency of the existing system. These technologies will impact how communication, navigation, and surveillance are conducted. In addition, increased levels of automation are expected to augment human performance. Planned changes to the system will include a move from radar-based surveillance to satellite-based navigation with Automatic Dependent Surveillance-Broadcast (ADS-B), increases in use of precision approaches through area navigation and required navigation performance, and a shift from centralized to distributed control [1]. 


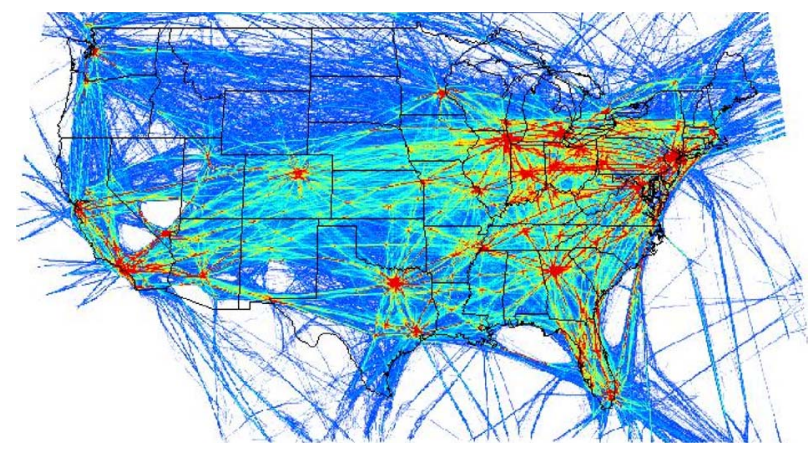

Fig. 2. Density map of $\mathbf{2 4}$ h of traffic in the United States.

However, implementing new aviation information systems and control paradigms in air transportation will be challenging due to complexities of the system and change process. As shown in Fig. 2, the air transportation system is also highly geographically distributed and structurally dependent. The multistakeholder nature of the system makes selecting system-level actions difficult when many stakeholders are affected in different ways and some favor a change while others oppose it. This is made more challenging by the distributed authority over different aspects of the system. For example, the FAA, operators, controllers, and pilots have varying responsibilities and levels of authority. International coordination and stakeholder interactions must also be considered when changes impact global operations, standards, and procedures.

Implementing system changes is also technically complex. Interactions among air- and ground-based avionics systems, air traffic control, weather, and surveillance technologies must be considered and accounted for. Potential failures and emergent behaviors must be recognized and corrected without creating dangerous situations in the system. This is particularly difficult due to the legacy elements of the system, which were developed slowly over time to address specific needs and can lead to interactions and unanticipated consequences when a change is introduced.

The high criticality of the system means there are high expectations for safety and operational performance. This results in a risk-averse setting where implementing new changing can be difficult if safety is not easy to prove. In addition, the system cannot be shut down in order to make such changes. As a result, a final change not only must be safe but also must be safely implemented while operations continue.

Because of the complex nature of the air transportation system, the availability of a specific technology or technological solution is not a sufficient condition to ensure its implementation. Technologies need to be considered in the context of the air transportation system. For this reason, it is important to understand how the system evolves and changes to achieve desired performance capabilities.

No literature exists attempting to understand the complete process of system change in air transportation. However, some work has been done to study aspects of change in the air transportation system. This work falls largely into three categories: plans for implementing a selected change [2], criticisms of plans or ongoing changes [3], [4], and evaluations or assessments of implemented changes [5]. The work presented in this paper generalizes aspects considered in prior work by developing a system-level model of change and applying it in multiple cases. The model incorporates work on understanding change in the policy domain [6]-[8] and on understanding stakeholder relations [9]-[11].

\section{FEEDBACK REPRESENTATION OF SYSTEM CHANGE}

Dynamics of change in the air transportation system can be represented as a simple feedback control process as shown in Fig. 3. The National Air Transportation System (NAS) is the

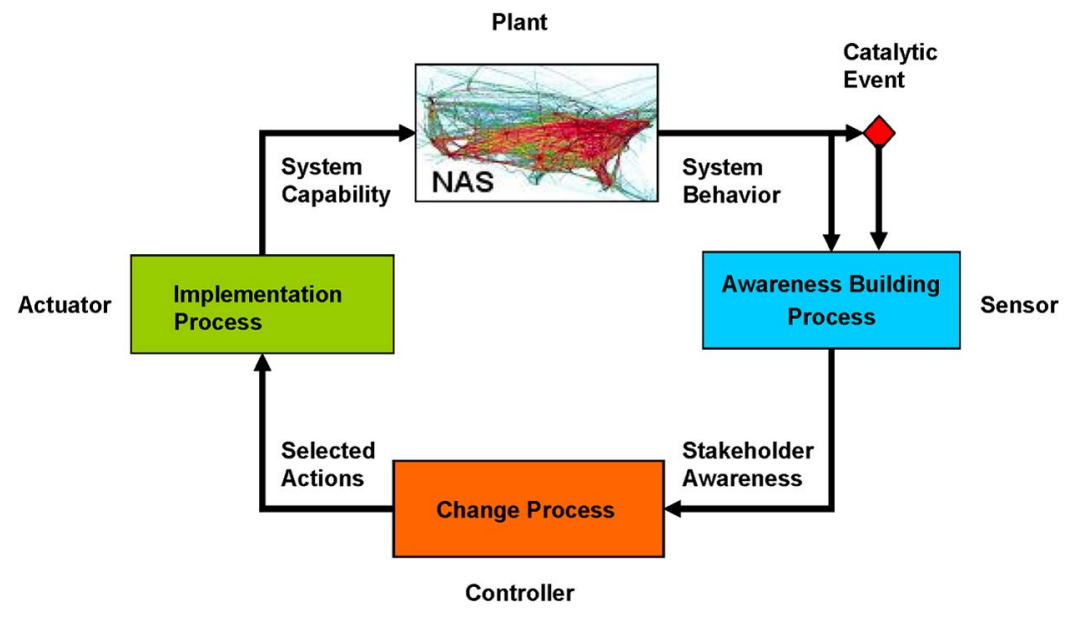

Fig. 3. Simple feedback representation of system change. 
plant in the system. System behavior is monitored during the awareness building process, which is analogous to the sensor. During this process, observable system states, which reflect system behavior, are evaluated and used to identify problems and opportunities. The change process is analogous to the controller and is where actions to address problems or opportunities are selected. The implementation process is analogous to the actuator, which enacts the decided-upon actions.

Identified problems and opportunities can often be grouped into categories that represent change drivers. Examples of drivers include problems and opportunities posed by system safety, capacity, environment, security, and emergent vehicle classes. Historically, most changes in the NAS were driven by safety problems. It was found that, in these cases, change was stimulated by aircraft accidents that acted as catalytic events, shown in Fig. 3, creating pressure for change.

\section{THE ROLE OF CATALYTIC EVENTS IN THE SYSTEM-WIDE IMPLEMENTATION OF INFORMATION TECHNOLOGIES}

Some information systems, such as flight management systems and ACARS datalink communications, have been incorporated into the aviation system without being preceded by accidents. However, after a thorough review of 27 cases of system transition [12], it was found that historically many implementations of aviation information systems into the air transportation system occurred in response to aircraft accidents. These accidents acted as catalytic events in the change process. The examples shown in Table 1 of past changes highlight a pattern of how aviation information systems are introduced into the system, as detailed in the FAA Historical Chronology [13].

Table 1 Example Catalytic Events and Resulting Aviation Information Systems Implemented

\begin{tabular}{|c|l|l|c|}
\hline & $\begin{array}{l}\text { Implemented Information } \\
\text { Technologies }\end{array}$ & Catalytic Event & Casualties \\
\hline A & $\begin{array}{l}\text { Positive Radar Control } \\
\text { implemented. }\end{array}$ & $\begin{array}{l}\text { Midair collision Grand } \\
\text { Canyon, AZ (June 30, } \\
1956) .\end{array}$ & 120 \\
\hline B & $\begin{array}{l}\text { Traffic Alert and Collision } \\
\text { Avoidance System (TCAS) } \\
\text { developed and mandated by } \\
\text { the FAA. }\end{array}$ & $\begin{array}{l}\text { Midair collision Los } \\
\text { Cerritos, CA (August 31, } \\
1986) .\end{array}$ & 82 \\
\hline C & $\begin{array}{l}\text { Ground Proximity Warning } \\
\text { System (GPWS) mandated } \\
\text { all aircraft with more than } \\
\text { 10 seats. }\end{array}$ & $\begin{array}{l}\text { Controlled Flight into } \\
\text { Terrain (CFIT) accident } \\
\text { Dulles, VA (December 1, } \\
1974) .\end{array}$ & 92 \\
\hline D & $\begin{array}{l}\text { Enhanced Ground } \\
\text { Proximity Warning System } \\
\text { (EGWPS) mandated. }\end{array}$ & $\begin{array}{l}\text { Controlled Flight into } \\
\text { Terrain (CFIT) accident } \\
\text { Cali, Colombia (December } \\
\text { 20, 1995). }\end{array}$ & 159 \\
\hline E & $\begin{array}{l}\text { Low Level Windshear Alert } \\
\text { System (LLWAS) } \\
\text { implemented at airports } \\
\text { with convective weather. }\end{array}$ & $\begin{array}{l}\text { Microburst accident New } \\
\text { York, NY (June 24, 1975). }\end{array}$ & 113 \\
\hline E & $\begin{array}{l}\text { Terminal Doppler Weather } \\
\text { Radar (TDWR) installed at } \\
\text { airports with microburst } \\
\text { activity. }\end{array}$ & $\begin{array}{l}\text { Microburst accident } \\
\text { Charlotte, NC (July 2, } \\
1994) .\end{array}$ \\
\hline
\end{tabular}

\section{A. Positive Radar Control}

The implementation of positive radar control began the current paradigm of radar-based air traffic control. In June 1956, a midair collision made it clear that the existing system was not scaling to safely keep pace with the growth of traffic. Two commercial aircraft requested, and were granted, a scenic detour into uncontrolled airspace over the Grand Canyon. Unfortunately, they did not see one another; the collision resulted into 120 deaths. The resulting outcry led to the hiring of 1400 new controllers, the deployment of additional towers and navigational aids, and implementation of positive control. As part of this change, radar was installed and all flight levels above 180 (18 000 feet) were designated as controlled airspace where aircraft would be monitored by air traffic controllers.

\section{B. Traffic Alert and Collision Avoidance System}

Although the implementation of positive radar control reduced midair collisions, they were not eliminated. In 1986, a general aviation aircraft inadvertently strayed into the controlled airspace around Los Angeles International Airport and collided with a commercial aircraft, resulting in 82 casualties, including 15 on the ground. Following this incident, the Traffic Collision Avoidance System (TCAS) was mandated and equipage required for all commercial carriers by 1994. TCAS provides warnings to pilots of possible midair collisions. Today, TCAS also provides a backup system for controllers during radar outages, allowing operations to safely continue rather than restricting flights in parts of the system while radars are repaired [14].

\section{Ground Proximity Warning System}

Controlled flight into terrain (CFIT), which occurs when perfectly operating aircraft are flown into ground or water, was also discovered and addressed following accidents. CFIT was one of the largest causes of aircraft accidents before it was addressed. An analysis of National Transportation Safety Board accident investigations provided insight into the nature of the problem and gave insight into a solution to be developed. The system, called the Ground Proximity Warning System (GPWS), provides warning to pilots when the distance between the aircraft and the ground below is too small. It was adopted by several airlines when it became certified. However, an accident was needed before that solution was mandated and implemented system-wide. That accident occurred December 1974 near Dulles, VA, when pilots unfamiliar with the terrain misunderstood a clearance given by controllers and descended too early. The GPWS was mandated that same month for large aircraft, which were equipped by 1976 . The mandate was extended in 1976 to all jet aircraft with ten or more seats. In addition, ICAO required equipage with GPWS in 1978.

\section{Enhanced Ground Proximity Warning System}

Although the frequency of CFIT accidents decreased significantly after the implementation of GPWS, CFIT was 
still a major safety threat. The solution to the CFIT problem was updated following an accident at Cali, Colombia, on December 20, 1995. The accident occurred because pilots entered incorrect data into the flight management computer and due to a miscommunication between pilots and controllers about which navigational aid was to be used. At this time, progress in technology allowed for an enhanced GPWS (EGPWS), which contained a database of terrain maps and could warn of potential CFIT crashes with terrain ahead of the aircraft and not only below. Following the accident, equipage with EGPWS was mandated by the FAA, requiring all aircraft with more than ten seats to be equipped by 2005 [13].

\section{E. Low-Level Windshear Alert System and Terminal Doppler Weather Radar}

A microburst is a weather phenomenon that can pose a large threat to arriving and departing aircraft. Microbursts create changes in wind direction that can reduce the lift experienced by an aircraft. If the aircraft is close to the ground, loss of lift can cause impact with the ground before pilots can recover. When accidents involving microbursts were first detected, there was a poor understanding of the phenomenon. Thus, an understanding of the weather pattern first needed to be developed. In this case, both research programs and incremental implementations of increasingly better solutions were spurred by multiple accidents. The first of these solutions was the Low Level Windshear Alert System (LLWAS), implemented soon after a microburst crash at Kennedy airport in June 1975. Research programs and technical improvements continued through the 1980s. Additional installations of LLWAS also occurred following accidents. The crash of a US Air jet in 1994 led to the installation of the Terminal Doppler Weather Radar (TDWR) at airports with common microburst activity. Since the implementation of TDWR at 44 airports around the United States, there have been no fatal accidents caused by microbursts at airports equipped with the technology.

\section{EMERGING DRIVERS OF SYSTEM CHANGE}

New drivers for system change are emerging. These include the need to increase system security following the attacks of September 11, 2001; system capacity constraints; increasing importance of environmental considerations; and the emergence of new vehicle classes such as UASs.

Security enhancements, like past safety changes, have been driven by catalytic events, such as the terrorist attacks of $9 / 11$ and hijackings to Cuba in the 1970s [13]. The 9/11 attacks resulted in tremendous awareness and pressure for change and resulted in significant technical, organizational, policy, and procedure changes. Other categories of change drivers are unlikely to have such high-profile events. The absence of a catalytic event results in different dynamics during the change process. Therefore, it is important to understand the nature of new drivers for system change and aspects of the drivers that influence how change is achieved.

Capacity constraints have emerged as one of the key issues motivating the need to modernize the U.S. air transportation system. Demand for air travel has been steadily increasing, as shown in Fig. 1, and is expected to continue growing [1]. However, the current system has not been able to scale to meet demand. This is evident in increasing national delays, shown in Fig. 4; and regional delays, shown for the New York area in Fig. 5. Fig. 4 shows both monthly delays and a 12-month moving average. The moving average shows that delays peaked during the summer of 2001 but decreased following the attacks of 9/11 when demand for air travel and, as a result, the number of operations significantly decreased. However, currently traffic has returned and surpassed the 2001 levels, bringing with it a return of delays. The figure also shows that the volatility of delays increased starting in 1998, evidenced by the higher amplitude in seasonal variability. This volatility is an early indication that the system is reaching capacity. In this condition, small perturbations, such as weather, propagate nonlinearly, causing significant delays throughout the system.

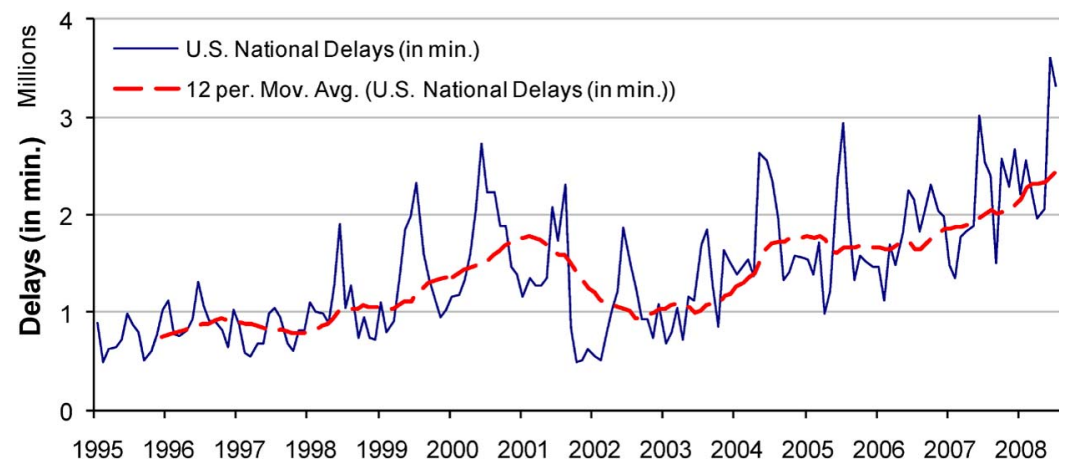

Fig. 4. National airport traffic delays [15]. 


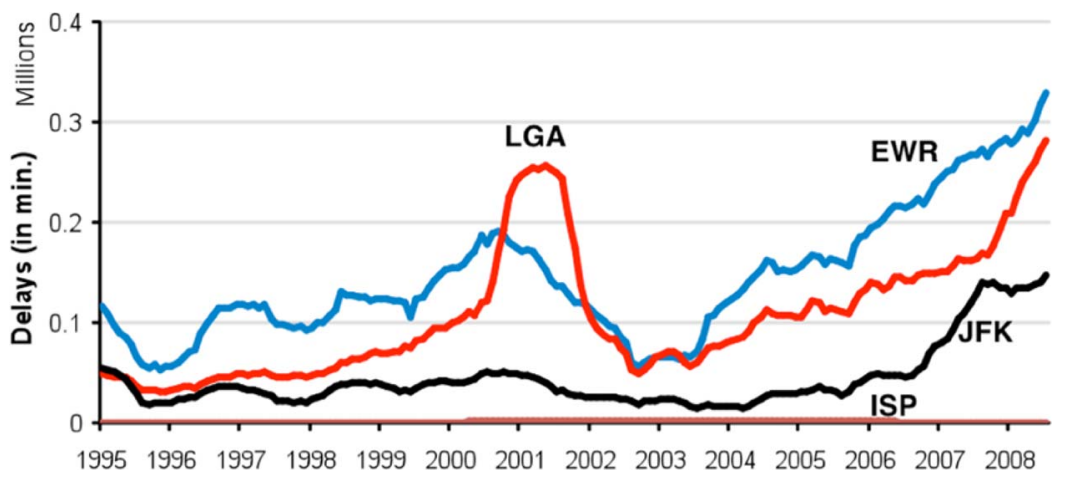

Fig. 5. New York airport traffic delays [15].

Environmental drivers-in particular, emissions and their connection to global warming - are becoming an increasingly important consideration in air transportation and other systems [16]. Europe is currently leading the way in attempting to limit emissions for aviation. However, pressure for change is expected to increase.

Emerging vehicle classes-in particular, UASs-pose an opportunity for new types of operations in the NAS. However, in order to accommodate such operations, the system must undergo significant changes as existing regulations, operating procedures, and certification procedures were all developed with the assumption that a pilot is operating the vehicle. UASs are currently recognized as emerging future users of the air transpor- tation system [17]. In particular, civil and commercial missions, but also military basing and training missions in the United States, are anticipated. The successful integration of UAS into the system will depend on overcoming this barrier.

\section{DETAILED DISCUSSION OF SYSTEM CHANGE PROCESSES}

The simple feedback model is expanded in Fig. 6 and is based on cases included in Section III and 14 additional cases of successful and unsuccessful technology changes in the NAS. In the absence of catalytic events, the multistakeholder nature of the air transportation system poses a

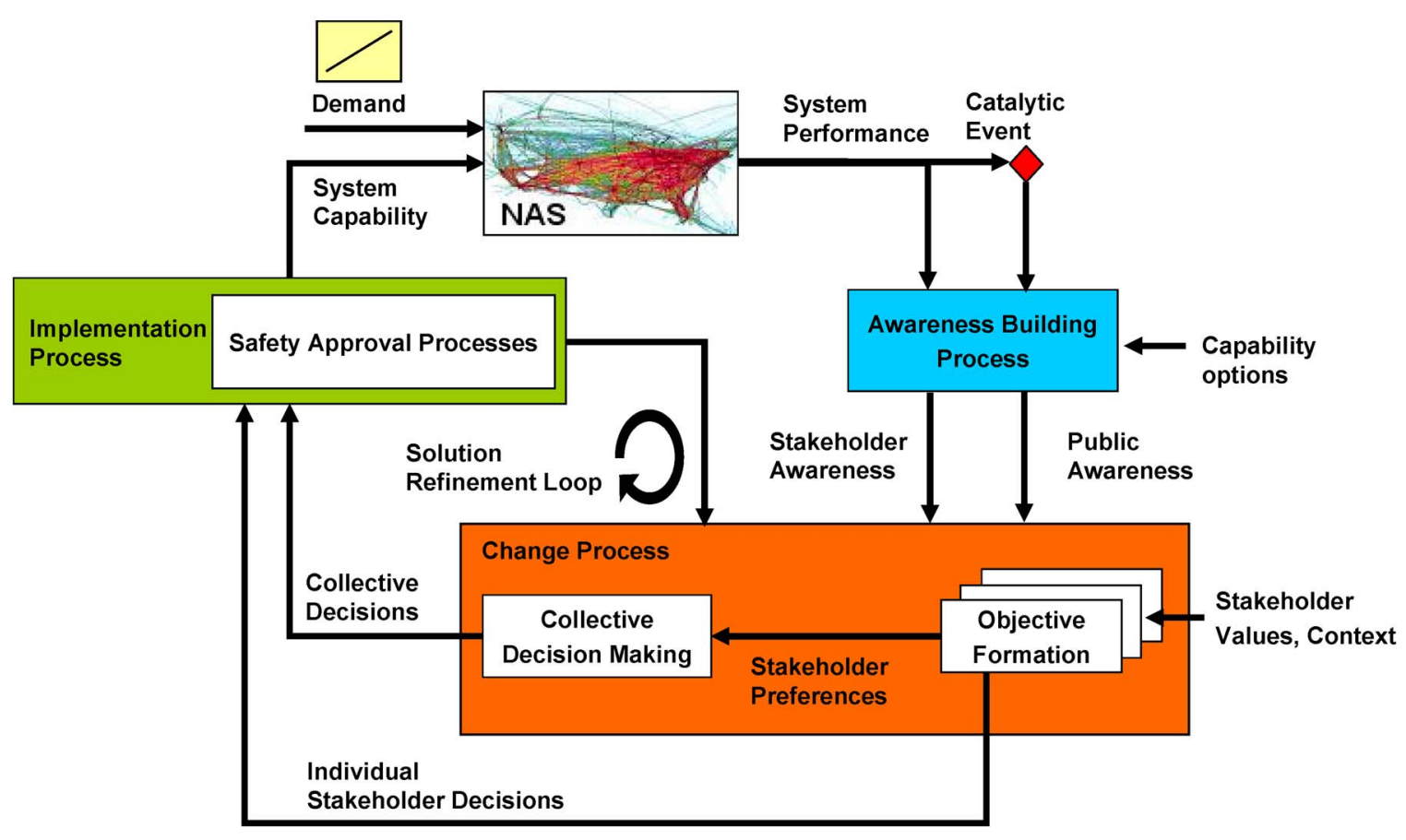

Fig. 6. Change dynamics process model. 
significant challenge for system change. In addition, long time constants associated with the implementation process delay the delivery of new system capabilities. Each of the major processes in the system change model is discussed below.

\section{A. Awareness Building}

System behavior is monitored during the awareness building process. As part of this process, stakeholders develop an understanding and definition of problems and opportunities that exist in the system. This is done through monitoring of system behavior as well as the analysis of information to understand the observed phenomenon. In some cases, system performance is monitored by designated agencies such as the National Transportation Safety Board, which investigates and tracks system safety. Stakeholders who interact with the system also monitor the aspects of performance that affect them. In addition, awareness of potential capability options is also developed. Based on available information, each stakeholder forms his own mental model of the situation, including projections of potential future states.

In the past, many changes in the air transportation system occurred in response to problems and following aircraft accidents. These accidents acted as catalytic events to stimulate system change by engaging the attention of the media and public to create pressure for change. The media plays a large role in shaping public awareness and public perception of risk [18]. Without accidents, the awareness of problems by stakeholders directly involved in the system was insufficient to create the pressure necessary to motivate leadership to take action. In contrast, changes in the system in response to opportunity are often driven by the existence of a new capability that provides the opportunity to improve system capability and deliver benefits to stakeholders.

In the absence of catalytic events, little public awareness of an issue exists. As a result, stakeholders are only aware of problems and opportunities as they affect them, creating a nonhomogenous awareness, varying stakeholder objectives, and little consensus for change [8]. Without clear catalytic events, change will become much more difficult to enact and barriers to change will prove to be more of an obstacle. There is a potential for both opportunity- and problem-driven change in the future; however, such changes will encounter strong barriers unless all stakeholders effected by the change benefit or there is a catalytic event.

\section{B. Change Processes}

During the change process, stakeholders evaluate the projections for the future and develop preferences or individual objectives for what actions they would like to see taken. The change process has two aspects. The first is where stakeholders independently determine their preferences. The second is a collective decision-making process where stakeholders interact to resolve different agendas to select collective actions. In some cases, individual action is all that is required to bring about a change, and resolving different stakeholder objectives is not an issue. However, in many cases, a collective action is also required. Because of nonhomogenous awareness that exists in the absence of catalytic events and the varying stakeholder interests that develop, resolving stakeholder differences can pose a challenge.

During a collective decision-making process, stakeholders work to influence decision makers and interact with others to determine if concessions and agreements can be reached. As shown in the model in Fig. 6, some cases require that operators commit to equipping their aircraft with technology and that the FAA provide the necessary ground infrastructure to support that equipage. In addition, the FAA must develop procedures and certify both them and the avionics.

For most major policy decisions, a cost-benefit analysis is required to weigh the overall benefit of a change [19]. This analysis generally considers the overall benefits of a technology, without considering distributions to individual stakeholders. However, the process by which stakeholder preferences and objectives are determined is complex and influenced by many factors, and an analysis that shows a positive net benefit on a whole may not be sufficient to motivate individual stakeholders to participate in a change.

1) Value Distributions and Objective Formation: Because of the nonhomogenous nature of air transportation system technologies, stakeholders have different individual appraisals of the value of a potential change. One way to represent stakeholder objective formation is through the value distribution, defined through the costs and benefits of a technology or proposed change [11]. The combination of cost and benefits delivered by a technology are referred to here as the value distribution. Within the change process, stakeholder objective formation is driven by the value gained from a potential technology, where value is the difference between benefits and costs.

Individual stakeholders examine the perceived value that a technology can provide to determine if it is of positive value to implement that technology. To understand cost and benefit dynamics by a stakeholder, a simple framework to describe value delivery is shown below. Distinct categories of benefits, such as fuel savings through efficiency improvements or reduced out-of-service costs due to increased utilization, could be provided by a technology or change. In this framework, a technology or change delivers multiple benefits, indexed by $i$, to multiple stakeholders, indexed by $k$. The benefit magnitudes are then considered for each combination $b_{i, j}$. Changes also come at a cost. This multidimensional cost is represented as $c_{j, k}$, where $j$ represents the cost category and $k$ represents the stakeholder. 
When examining value distributions for stakeholders in the system, there are several important factors to consider. First, stakeholders evaluate positions on technology based on perceived costs and benefits, which may differ from the actual costs and benefits delivered. As an example, the benefit of a technology may be discounted by stakeholders if they perceive that is not easily achievable or easily implemented. Secondly, costs and benefits can be appraised differently by different stakeholders, depending upon their context in the system. Individual stakeholders derive a level of benefit from the adoption of a technology. This benefit is the sum across all benefit categories, as shown in (1). The aggregate cost paid for a technology is the sum across cost categories, as shown by (2)

$$
\begin{aligned}
& B_{\mathrm{i}}(t)=\sum_{\mathrm{k}=1}^{\mathrm{n}} \mathrm{b}_{\mathrm{i}, \mathrm{k}} \\
& C_{\mathrm{j}}(t)=\sum_{\mathrm{k}=1}^{\mathrm{n}} \mathrm{b}_{\mathrm{j}, \mathrm{k}} .
\end{aligned}
$$

2) Temporal Delivery of Costs and Benefits: In addition to considering the distribution of costs and benefits across stakeholders, it is also necessary to examine the temporal distribution of costs and benefits to individual stakeholders. A key issue that will reduce the value of a proposed technology or change is the perception that benefits will be delayed or will not be delivered due to a variety of factors after a supporting technology is already acquired and installed. To describe issues in temporal delivery of costs and benefits, implementation of aviation information systems can be evaluated using investment analysis. The parametric model that follows is a general framework for evaluation of discounted costs and benefits proportional to fleet equipage similar to the methodology used by the FAA to evaluate the financial balance of the proposed ADS-B out rule [31].

In this example, investment decisions are made by operators to equip a fleet of aircraft $n_{\text {fleet }}$ with a technology that will require payment of costs and receipt of benefits as a function of time in operation. For this, costs are decomposed into two factors: acquisition costs and operational costs. Installing the equipment then results in operational benefits. The number of aircraft equipped $n_{\text {equip }}$ at time $t$ is modeled using the Gaussian function centered around a mean time $T_{\text {mean }}$ and with standard deviation parameter $\sigma$ shown in (3). This functional form is used to approximate the variance with time of maintenance cycles used for equipage

$$
n_{\text {equip }}(t)=n_{\text {fleet }} \frac{1}{\sigma \sqrt{2 \pi}} e^{-\left(\frac{t-t_{\text {mean }}}{2 \sigma^{2}}\right)^{2}}
$$

Expanding the model in (4), acquisition costs paid at time $t$ are assumed proportional to the number of aircraft equipped in an operators' fleet $n_{\text {equip }}$ at a unit acquisition cost per aircraft of $C_{\text {unit_acq. The acquisition cost function }}$ accounts for costs such as the purchase and installation of equipment, aircraft out-of-service costs during installation, crew training, and certification costs

$$
\begin{aligned}
C_{\text {acq }}(t) & =C_{\text {unit_acq }} n_{\text {equip }}(t) \\
& =C_{\text {unit_acq }} n_{\text {fleet }} \frac{1}{\sigma \sqrt{2 \pi}} e^{-\left(\frac{t-t_{\text {mean }}}{2 \sigma^{2}}\right)^{2}} .
\end{aligned}
$$

Total acquisition is calculated from the integral of incremental acquisition cost over time, as shown in (5)

$$
C_{\text {tot_acq }}(t)=\int_{t=0}^{\infty} C_{\text {unit_acq }} n_{\text {fleet }} \frac{1}{\sigma \sqrt{2 \pi}} e^{-\left(\frac{t-t_{\text {mean }}}{2 \sigma^{2}}\right)^{2}} d t .
$$

As modeled in (6), operating costs include recurring maintenance on the equipment, potential subscription or service rates, or depreciation of equipment. Operating costs at a given time $t$ are modeled as proportional to the total number of aircraft equipped from (3) multiplied by the unit cost of operation per piece of equipment $C_{\text {unit_op }}$. The total number of aircraft equipped at a given time is given by the cumulative distribution function of equipage $\Phi_{\text {equip }}(t)$, as shown in (6)

$$
\begin{aligned}
C_{\text {op }}(t) & =C_{\text {unit_op }} \int_{0}^{t} n_{\text {fleet }} \frac{1}{\sigma \sqrt{2 \pi}} e^{-\left(\frac{x-t_{\text {mean }}}{2 \sigma^{2}}\right)^{2}} d x \\
& =C_{\text {unit_op }} n_{\text {fleet }} \Phi_{\text {equip }}(t) .
\end{aligned}
$$

In this example, operational benefits can include multiple categories of benefits, such as operational efficiency savings, cost avoidance, or prioritized access to resources, depending on the structure of the program. Operational benefits are modeled proportional to the number of aircraft equipped at a unit benefit of $B_{\text {unit_op, }}$ similar to operational costs. Delivery of operational benefits is assumed to require the implementation of supporting infrastructure and operational approval to utilize the technology and infrastructure. Therefore, benefits can be delayed relative to equipage. To model the effect of delay in the delivery of benefits, benefits are assumed to begin at a time $T_{\text {delay }}$ when a given percentage of the fleet has already been equipped. Thus, the benefits function is defined piecewise, as shown in (7). After $T_{\text {delay, }}$, 

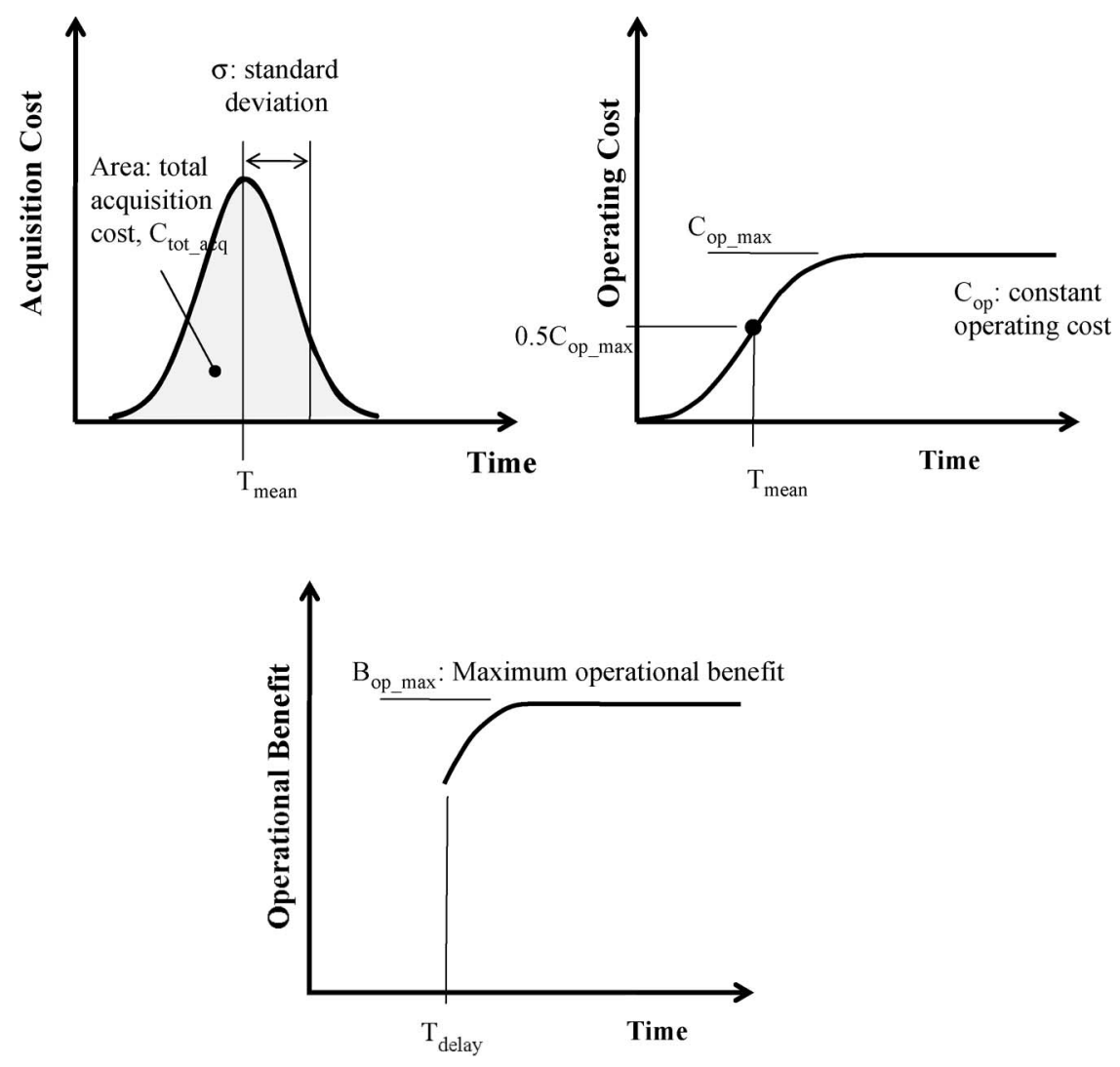

Fig. 7. Cost/benefit temporal distributions.

benefits are proportional to the cumulative fleet equipage. No benefits are delivered before $T_{\text {delay }}$

$$
B_{\text {op }}(t)=\left\{\begin{array}{lr}
0 & \text { for } \begin{array}{r}
t<T_{\text {delay }} \\
t>T_{\text {delay }}
\end{array}
\end{array}\right.
$$

Equations (3)-(7) describe a simple model of acquisition costs, operating costs, and operating benefits. These factors are summarized in Fig. 7, which shows the distribution of costs and benefits as a function of time.

Representing the technology or change adoption decision using investment analysis, the net present value NPV of a given combination of costs and benefits is indicative of the attractiveness of investment. The net present value is calculated by discretizing costs and benefits to annual net cash flows. Future cash flows are discounted at a rate $\gamma$. The resulting NPV is shown in (8)

$$
\mathrm{NPV}=\sum_{t=0}^{t=T} \frac{B_{\mathrm{op}}(t)-\left[C_{\mathrm{acq}}(t)+C_{\mathrm{op}}(t)\right]}{(1+\gamma)^{t}}
$$

3) Example Equipage Evaluation: To illustrate issues in temporal aspects of value delivery, the simple model introduced in (3)-(8) is used to describe the influence of several equipage parameters. For the analysis, several assumptions were made. In the absence of specific cost and benefit data, the acquisition total acquisition cost $C_{\text {acq_tot }}$ was normalized to unity. Additional trades are presented as multiples of total acquisition cost or unit operating cost. For example, a displayed NPV/ $C_{\text {acq_tot }}$ of 1.5 indicates a present value of 1.5 times the total acquisition cost.

Additionally, a standard discount rate $\gamma$ of $7 \%$ was applied to future benefits, and a unit operational to acquisition cost ratio $\left(C_{\text {unit_op }} / C_{\text {unit_acq }}\right)$ of $10 \%$ was assumed. Acquisition costs were distributed around a mean time of five years, with a standard deviation of two years, indicative of $95 \%$ equipage within an eight-year time span. The magnitude of benefits was varied as a ratio to operating costs, essentially varying net benefits. An NPV over 25 years of operation is indicative of the attractiveness of equipage over an approximate system's life cycle, although in business decisions financial return would certainly be required sooner. The effect of delaying the implementation of benefits (i.e. varying $T_{\text {delay }}$ ) on NPV under these assumptions is shown in Fig. 8. The benefit/ cost ratio required for a break-even NPV for different delay times can also be determined, and is shown in Fig. 9. 


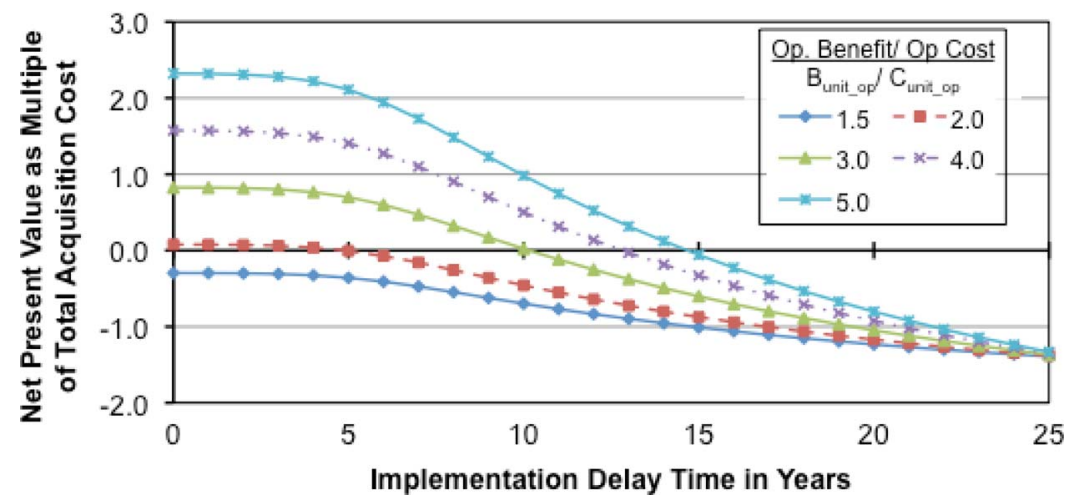

Fig. 8. Influence of implementation delay on net present value (assumed $7 \%$ discount rate, $10 \%$ operational to acquisition cost, normally distributed equipage with mean of five years, and standard deviation of three years).

Because of up-front acquisition costs, early cash flows are strongly negative. Therefore, large net operational benefits are required to pay off the initial investment. The NPV is negative for any implementation time when the magnitude of operational benefits is just under twice the operational cost. Even when benefits are high, delaying implementation significantly reduces the net present value of equipment, especially beyond the acquisition time period (approximately eight years). If benefits are delayed significantly, levels of operational benefits have a weaker influence. The net present value becomes negative regardless of the magnitude of benefits within the range shown after 15 years.

Time delays in benefits delivery occur due to a mismatch between acquisition times and delivery of operational benefits. Causes of this mismatch can include dependency on other stakeholders to equip with similar technology or requirements for certification before using the technology. Perception of delays is also a strong disincentive for equipage. If stakeholders incorporate uncertainty into their estimate of benefit delivery time or magnitude due to risks of benefit delivery, technology value is reduced.

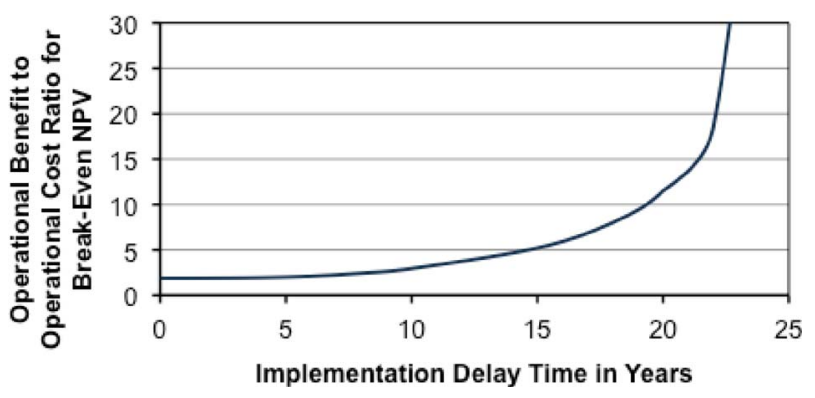

Fig. 9. Benefit magnitude required for break-even NPV (same assumptions as above).
To structure successful technology adoption, it is useful to reduce the delay of benefits delivery as much as possible. This can be done by decoupling equipage decisions from those of other stakeholders or isolating the certification requirements to single system components such as operational procedures or avionics. Leverage mechanisms can also be used. Reimbursement of acquisition costs reduces the initial up-front payout for technology, accelerating benefits delivery. Mandates create certainty in future benefit delivery dates and reduce discounting due to uncertainty. Policies can also increase the magnitude of benefits for early adopters by allowing preferential access to airspace or operational cost deferment.

\section{Implementation Process}

The implementation process transforms solutions to a problem developed in the change process from concepts to actual operation in the system. There are several challenges in implementing new aviation information systems. One major risk to delivery of benefits to stakeholders is the ability to achieve operational approval for the large scope of planned future changes. As shown in Section IV-B, accelerating the delivery of benefits strongly increases the value of a technology or change. Therefore, it is necessary to examine issues in the operational approval and implementation of aviation information systems to help accelerate operational approval processes.

Fig. 10 shows processes involved in implementing a new operational technology. Aviation information systems are considered as part of overall concepts of operations. Separate operational approval steps are required for airborne components, operating procedures, and groundbased components of change [21]. Any single information technology may exhibit combinations of changes in different areas. Regardless of the combination, operational approval of the overall system is required before a new operational capability can be achieved [22]. The solution refinement process presents significant challenges for 


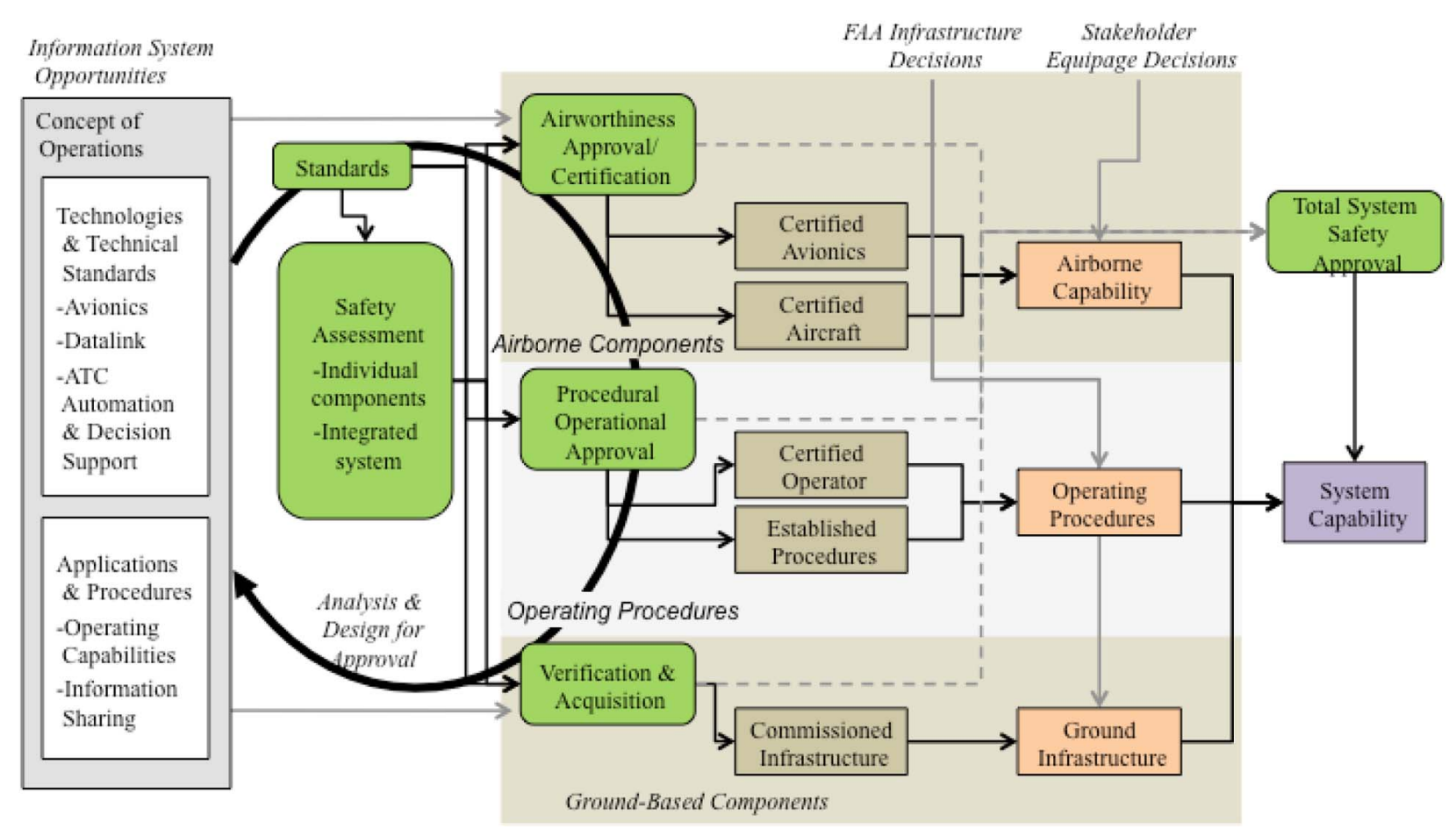

Fig. 10. Safety assessment and implementation process.

achieving technological change. It consists primarily of safety assessment of proposed changes to ensure that they can receive operational approval at an acceptable level of safety. This process, while necessary, can introduce substantial delays and uncertainty into the transition process and has been observed to have a "cycle time" longer than the underlying technology certified [21].

Achieving operational approval is becoming increasingly challenging, as observed RTCA Task Force 4 on Certification [21]. Operational concepts require increasing integration and assessment across multiple system components and domains, with technology changes in airborne and ground components, and interaction through operating procedures. This has increased the complexity of the safety assessment and approval process, requiring identification of potential emergent behavior and system interactions.

As shown in Fig. 10, operational approval requires proving that a proposed change meets a certification standard. Two approaches to assessing the safety of a change exist. The first approach is to evaluate a change to a reference target level of safety, which can be quantitative or qualitative. In this approach, potential failure modes and system interactions must be identified and addressed, and the level of safety expected in the system change must be approved by certification authorities [22]. Along with increasing safety of air transportation [24], the scrutiny applied to new system changes has increased. New safety assessment processes have been put in place to ensure a rigorous process in evaluating all potential hazards associated with a change, such as the Air Traffic Organization's Safety Management System [22]. Increasing safety expectations coupled with the expanding magnitude of planned changes will result in increasing challenges to achieving operational approval for implementation of new technologies.

The second approach is to evaluate a change in comparison to a reference system, known as using an "equivalent level of safety approach." This approach is typically possible for technologies that perform equivalent functions to current systems, such as replacement surveillance systems. Using this approach, the replacement system is designed to perform equal to or better than the system it replaces by relevant attributes [23]. As fundamentally new capabilities are introduced into the system, the equivalence approach becomes too limiting to achieve changes sufficiently different from current systems.

A challenge in the operational approval process is to maintain stability in the definition of technical standards. Due to the long time-scales of change, several factors can cause a change in system components: the underlying technology can change, performance requirements can change as new experience is gained, or stakeholders can choose different technical solutions. The instability of system requirements increases the potential for making the investment of early adopters obsolete if the earlier technology does not meet required performance standards. There is a fundamental tension between refining standards 
and ensuring that changes are flexible to accommodate new technological solutions.

Software is emerging as a significant component in future systems. As opportunities for expansion of physical architecture decrease, information systems and software are increasingly used to add system capabilities. There are several challenges in software certification. How to demonstrate that software can meet claims for dependability is still a subject of ongoing refinement [25]. Software also tends to be a high-cost component of current systems, and the ability to reuse software development between certification projects is limited [25].

The increased coupling of new system changes results in challenges due to different approval processes for air and ground components. Historically, air and ground systems were certified separately. For example, design assurance standards differ between airborne [26] and ground-based components [27]. Design assurance standards also increase for more safety-critical applications of technology. Because of mismatches in program timecycles, areas of system infrastructure can be deployed and certified to a level that does not support more critical applications that may be used in the future.

The operational approval process issues discussed above increase the risk of realizing future benefits of equipage.

\section{EXAMPLES OF SYSTEM CHANGE EFFORTS}

Two examples of current system change efforts in the NAS are shown in the following sections to discuss the issues above. These examples are the implementation of ADS-B and the integration of UASs into the NAS. ADS-B was selected as an example of an integrated system change that requires avionics and ground infrastructure as well as individual and collective actions. UAS was selected as an example of opportunity-driven change that faces significant challenges to achieve operational approval within the system.

\section{IMPLICATIONS FOR ADS-B IMPLEMENTATION}

\section{A. ADS-B Functionality and Implementation Approach}

ADS-B is considered as one of the fundamental technologies for integration of new applications and capabilities both in the United States [28] and Europe [29]. ADS-B is a surveillance technology that broadcasts aircraft-based position and other states (usually derived from GPS) to ground-based receivers and other aircraft. This datalink enables a variety of capabilities on the aircraft and in air traffic control, as shown in Fig. 11. Broadcast to other aircraft and the ground is named ADS-B-out. Because of the presence of a datalink, aircraft can also receive ADS-B information from other aircraft and receive information from the ground. This functionality is known as ADS-B-in.

ADS-B is currently planned to be deployed in segments. Segments one and two of the ADS-B program will enable capabilities in the cockpit and in air traffic control surveillance, shown in Fig. 11. In the cockpit, ADS-B is used to augment pilot situational awareness through ADS-B-in display and information. ADS-B-in applications include

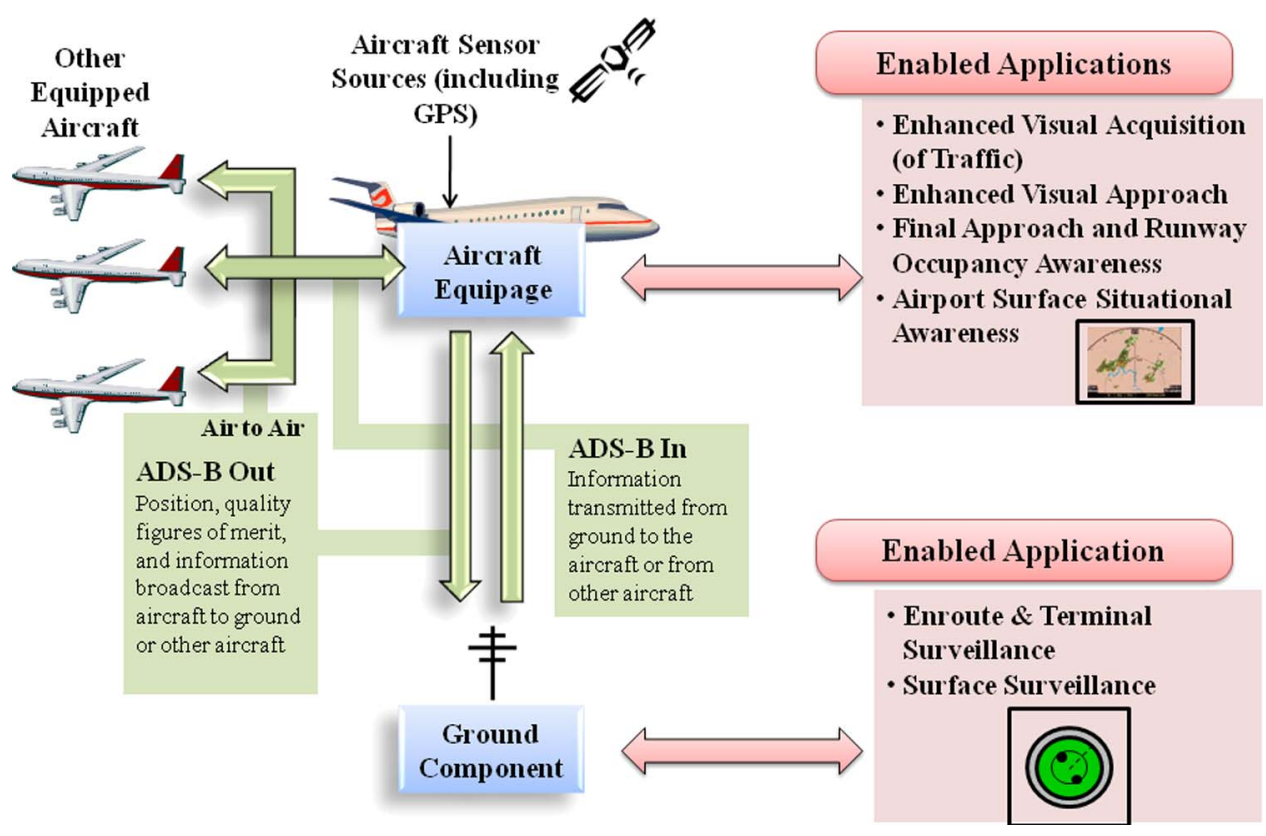


enhanced visual acquisition (of traffic), enhanced visual approaches, final approach and runway occupancy awareness, and airport surface situational awareness [30]. Broadcast of weather and other aeronautical information also provides additional situation awareness. Integrated with air traffic control, ADS-B-out will be incorporated as a surveillance source for air traffic control services and to support separation of aircraft on the surface and in the enroute and terminal environment [30]. Segment 1 is limited in geography to initial "key sites," while segment two denotes the deployment of ADS-B applications throughout the NAS.

In the future, more accurate position information, available through ADS-B, offers the opportunity to reduce separation standards. Cockpit-based traffic also provides the potential to delegate separation responsibility from air traffic control to the cockpit under certain conditions. However, these applications are not being implemented in the initial phases of ADS-B deployment.

\section{B. ADS-B Costs and Benefits}

Aviation information systems can deliver different benefits to different groups of stakeholders. In ADS-B, benefits delivery depends upon the applications implemented. ADS-B-out is expected to be mandated (subject to final approval) [20], but ADS-B-in equipage is voluntary. Therefore, equipage decisions made by individual stakeholders depend upon the portfolio of applications that they chose to equip. The magnitude of benefits will depend on specific operational context and applications implemented. In parallel to the information system adoption modeling process, a detailed survey of ADS-B users was performed to determine key issues in implementing ADS-B applications and differences in benefit perceptions between users [32]. The survey responses showed that there are benefits perceived by different types of operators, but there is a general perceived lack of certainty in delivery of benefits due to several issues discussed in the following sections.

1) Stakeholders and the Change Process: Many changes involving a large number of stakeholders not only need stakeholder differences to be resolved but also require cooperation to be successful. In such cases, stakeholders depend on others to fulfill their part of the transition process before their benefits can be realized. This is shown in the model of Fig. 6 as dependencies on individual stakeholder decisions and collective decisions before implementation. Such dependencies can materialize as uncertainties in the cost-benefit analysis conducted by stakeholders and impact their objectives. The case of ADS-B is one where such multistakeholder dependencies may play a large role.

There are three significant sources of risk associated with ADS-B implementation. The first is that a critical mass of equipage needs to be reached before stakeholders can begin to receive benefits of implementation. As a result, stakeholders are dependent on the actions of others for ADS-B to be successful. Because there is no guarantee that other operators will equip, there is an incentive for operators to postpone implementation and be the last to equip. In this way, they can minimize uncertainty about the actions of others. However, as each stakeholder postpones equipage, benefits are also postponed, resulting in a less favorable NPV.

Providing incentives for equipage is a potential leverage strategy that can be used to overcome this barrier. However, when insufficient individual equipage for delivery of benefits does not occur, it may become necessary to mandate equipage to gain full benefits. A mandate indicates that those without equipage will not have access to airspace adding significant costs to those who do not equip. In current plans, the FAA is seeking to encourage early voluntary equipage but recognizes the need for an ADS-B mandate in 2020 [20].

The second risk deals with which applications of ADS-B will be supported and when. Both the level and timing of benefits will be impacted by the selected applications and their timing.

2) Cost and Benefit Implications: The third source of risk deals with the ability and timing of the FAA's infrastructure deployment and completion of safety and certification processes. In order for operators to gain benefits from ADS-B equipage, the FAA has to ensure the availability of ground infrastructure, stable technology and procedure requirements, and certified technology for operator equipage. As a result, the certification and approval process can be a key barrier to implementation if there are difficulties carrying out this process. If these implementation processes are delayed, the benefits will be delayed as well.

FAA estimates of ADS-B out costs and benefits performed to support rulemaking provides an example magnitude of the implementation delay effects illustrated in According to the FAA study, the total midrange, undiscounted equipage cost is $\$ 1.4$ billion for the entire U.S. jet fleet from 2012 to 2035. Cost of equipment carriage (in increased fuel burn), repair, and replacement was estimated as \$118 million. According to the cost/benefit analysis shown in Fig. 8, operational benefits to cost on the order of two would result in a positive NPV. Using the FAA analysis implies that operational benefits must be on the order of \$236 million [31] over the same period to result in a positive net present value. A positive return is relatively insensitive to delay time up to approximately ten years.

\section{Sources of Uncertainty in ADS-B Implementation}

1) Requirements Stability: Because standards are developed before certification of procedures, there is significant uncertainty in potential costs of recertification or reequipage if the avionics installed by early adopters are not adequate to perform desired functions. This problem occurred during the development of DO-260, which is the 
Minimum Operational Performance Standards (MOPS) for the $1090 \mathrm{MHZ}$ extended squitter (1090ES) [33]. Early avionics based on the DO-260 standard allowed for the use of either of two potential measures of position uncertainty. During later revisions, only one of these measures was determined to be acceptable for use in air traffic control (ATC) separation. As a result, the installation of ADS-B avionics in individual aircraft must be modified to use the approved method of broadcasting position uncertainty. As an example, Airservices Australia currently has to certify each individual airframe before the aircraft could utilize ADS-B for ATC separation [34].

The DO-260 specification has been changed once, to the current DO-260 Change 1 . The second version of the 1090 ES MOPS, DO-260A, has been changed three times, with the current version published as DO-260A Change 3. The MOPS for the Universal Access Transceiver, the datalink standard that supports graphical weather information, has also gone through two major revisions, with the current revision being DO-282A. These revisions illustrate that there is no guarantee that further changes will not occur. In fact, the contract award for broadcast services is likely to stimulate further avionics development and standard revisions. Uncertainty in standards creates a disincentive for operators to equip with a technology that meets the current standards if their avionics may not be usable in the future or if revised standards provide a higher level of benefits.

2) Varying Criticality Levels: A Notice of Proposed Rulemaking (NPRM) has been published with an anticipated requirement for ADS-B-out equipage for access to certain areas of airspace by 2020 [20]. It is expected that some users will evaluate a decision to equip earlier than the mandate based on benefits of both ADS-B-out and ADS-Bin applications. For segments one and two, a limited set of ADS-B-in applications is being implemented. Air traffic control surveillance is classified as a critical NAS service. Yet, the currently supported cockpit-based applications augment situational awareness and are therefore classified as essential services. Classification of services as higher criticality places requirements on system performance that are more stringent. As an example, critical services have higher availability requirements and lower probability of failure requirements than essential services [35]. In addition, specific cockpit design attributes, such as placement in the primary field of view, may be required to receive airworthiness certification. Several lower level performance measures also depend on the higher level specifications, such as system latency and update rate.

Several applications envisioned for future use of ADS-B, such as self-separation, would require airborne avionics to support a higher level of flight criticality in ADS-B-in applications. Because of the mismatch between design assurance levels to support essential cockpit-based services, and potential future flight-critical uses, there is a concern that current airborne specification of the system may not be sufficient to support future uses, and additional standards in equipage would be needed because the same avionics and infrastructure would be used for multiple applications.

The discussion above illustrates a fundamental system tradeoff between designing for current compared to future capabilities. The applications for which ADS-B is used will set specific performance requirements across the system, such as position integrity and accuracy. The current NPRM-mandated values are based on an RTCA assessment of surface application requirements [20], while other applications, such as nonradar airspace operation, have been assessed to lower requirements by similar methods [36]. There is also a potential that ground infrastructure design assurance, including software and data integrity, may not be sufficient to support future flight-critical cockpit-based applications. While some safety assessment and modeling activities are used to inform the development of RTCA standards, the FAA is ultimately responsible for safety certification of ADS-B procedures. This analysis is performed to determine ground infrastructure requirements and procedural mitigations to arrive at an acceptable level of safety, according to the FAA's Safety Management System process [22].

Avionics and operational procedures are approved through a different process. Intended uses of avionics are certified as part of operator type certification, and specific avionics packages are certified through the airworthiness certification process. Avionics development and certification usually occurs after ground infrastructure has already been specified and deployed. As a result, ground infrastructure requirements are fixed while avionics are still changing potentially resulting in incompatible systems.

3) Equivalent Versus Target Levels of Safety: As currently specified, ADS-B will be a replacement surveillance source for current radar separation procedures. As a result, the use of ADS-B can be certified using an equivalent level of safety approach. This approach requires demonstration that ADS-B performs equivalent to current surveillance sources and is therefore easier to achieve than performing an analysis to a target level of safety. However, reduction in separation standards requires an assessment to a target level of safety before procedures can be approved [23]. Assessing changes to a target level of safety is significantly more difficult because it is performed to an absolute instead of relative standard. As an example, performing a target level of safety assessment to support the implementation of reduced vertical separation minima in European Union airspace required approximately ten years to conduct [37]

\section{IMPLICATIONS FOR UNMANNED AIRCRAFT SYSTEMS INTEGRATION}

\section{A. Opportunities for Unmanned Aircraft}

The attractiveness of UASs for operation in commercial airspace presents an example of an opportunity-driven 


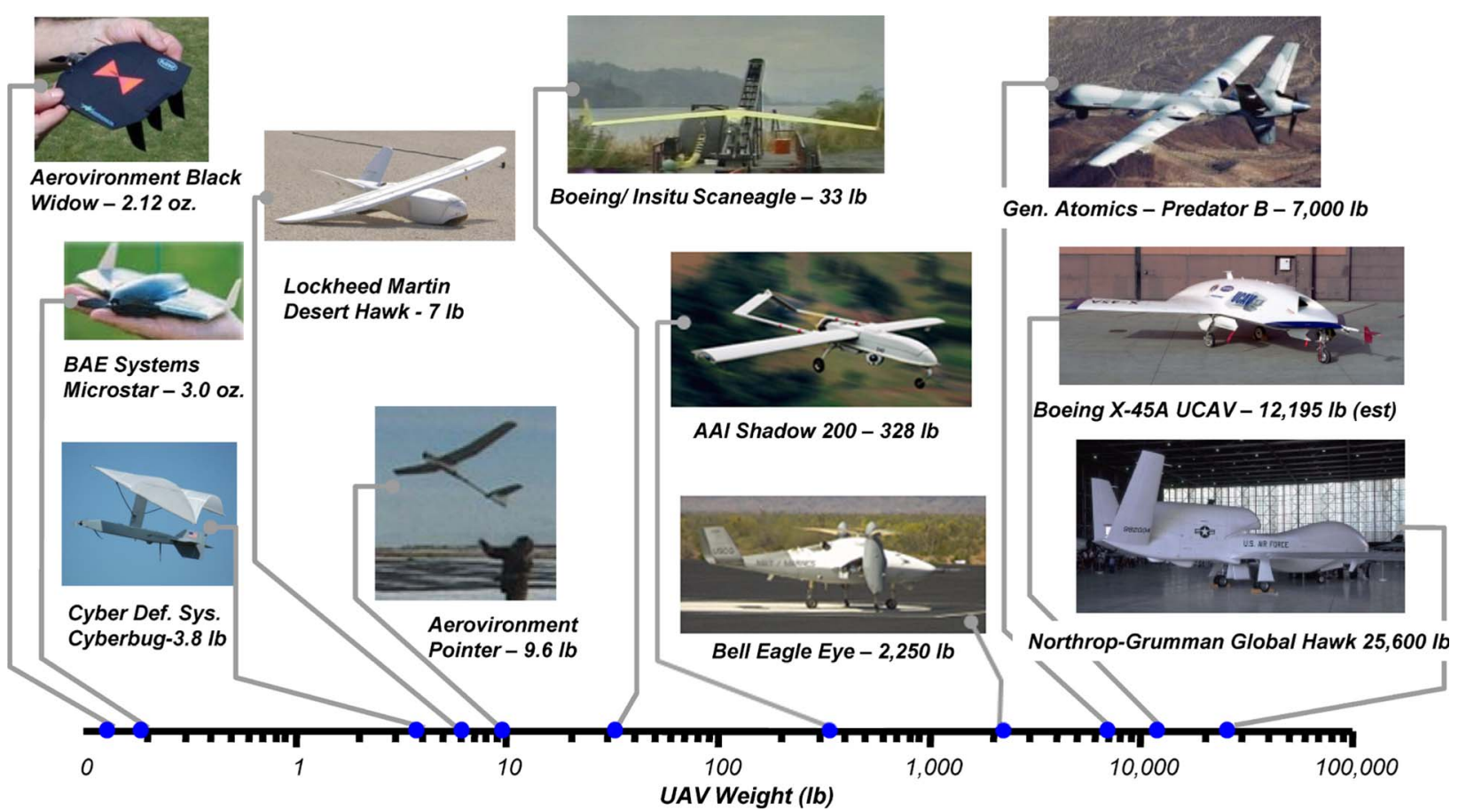

Fig. 12. Mass spectrum of unmanned aircraft systems.

change to the air transportation system. Unmanned aircraft have been used extensively in military operations, with platforms spanning a broad range of sizes and operational capabilities, as shown in Fig. 12. Realization of commercial potential has been limited to this point, but stakeholders are becoming increasingly aware of the new capability options that UAS operation provides.

\section{B. Current Applications and UAS Operations}

Within the change process shown in Fig. 6, there is currently ongoing assessment of the value of unmanned aircraft for civil applications. Current civil and commercial applications of UAS in the United States have been limited to demonstration projects for law enforcement, border patrol, hurricane monitoring, and wildfire sensing and response. The strongly perceived public benefit of the use of UASs in border surveillance has driven the early emergence of the application. An associated strong need by the military to conduct training operations has resulted in a development program for national access. Although the use of UAS by the Department of Homeland Security is growing, there are still significant airspace restrictions placed on their operation.

Opportunity-driven change in the case of UAS has been difficult to implement due to the unprecedented nature of the operational concept. Realizing routine access has been especially challenging because there is dependence on new infrastructure to enable operational capabilities, in addition to individual stakeholder equipage decisions. Current federal aviation regulations did not anticipate the opera- tion of unmanned aircraft. Consequently, the regulatory infrastructure is not present. Functional requirements for operation in the NAS, such as avoidance of other air traffic and communication with air traffic control, are straightforward for piloted aircraft but have not been interpreted for unmanned aircraft. Current UASs are operated based on a limited FAA approval issued for each type of operation [38]. In addition, an RTCA committee has been established to identify recommended standards to enable routine UAS operations, provided sense and avoid and control and communications capabilities were adequate.

Infrastructure deployment and implementation activities are coupled. Infrastructure investment makes sense only if numerous operations are anticipated. However, investment in operations is risky when infrastructure does not yet exist. Difficulty in resolving this impasse has resulted in the current solution to limit the operational scope of UAS and limit the number of stakeholders involved. One result of this has been to restrict commercial applications of radio-controlled models, such as aerial photography. Radiocontrolled aircraft are allowed to be operated for recreational use under existing policies but are not authorized for similar profile missions for commercial use [39].

\section{Future Prospects and Challenges}

In other countries, modification of infrastructure and regulations has advanced civil applications of UASs. Autonomous helicopters are routinely used for agricultural spraying in Japan [40], and aerial photography operations using small unmanned aircraft are regulated in Australia [41]. In both 
cases, regulatory decisions were made to allow commercial operations as long as they do not interact with other air traffic. To realize the full range of potential UAS operations, integration with the system must be considered [42], but this requires system capabilities and vehicle capabilities that do not presently exist. The development of these capabilities will require the involvement of a larger range of stakeholders.

Because of the need for increased onboard autonomous capability, UASs push the state of the art in the application of decision-support and aviation information systems in aviation. Substantial effort has been performed developing technological solutions to augment or replace performance currently demonstrated by manned aircraft. Examples include autonomous planning capabilities, detection of aircraft and other objects such as terrain, communication with air traffic control, and innovative control capabilities. A key challenge will be to develop these capabilities to a level that can be certified as safe. Without specific performance standards for capabilities, the solution refinement process shown in Fig. 10 can require substantial investment, as potential changes must be assessed probabilistically [43], and current safety targets required are uncertain.

Unmanned aircraft also continue the trend toward more distributed decision-making, with potentially increased reliance on onboard autonomy in such functions as flight path planning, lost link capability, and avoidance of other air traffic. Development and certification of software becomes an increasing challenge, as software assumes more flight-critical functionality previously performed by the human. Current software development standards make it difficult to verify complex or emergent behavior that may be uncovered in the system outside of previous experience. Resolving this difficulty will be key to achieving benefits from UAS operations.

\section{CONCLUSION}

Effective implementation of new aviation information systems into the air transportation system is a key capability necessary to address current capacity shortfalls and other deficiencies in system performance. The feedback model described in this paper illustrates several factors that remain important to achieve system change. These include understanding and anticipating multistakeholder interactions and conflicts, development of capability options, improving the efficiency of safety approval processes, and addressing requirements stability for new system capabilities.

Research in aviation information systems is valuable in providing capability options as potential solutions to system performance shortfalls. When demand for improved performance manifests, this early research can server as a foundation for solution development and implementation and can accelerate the overall change process.

Understanding of multistakeholder cost-benefit dynamics is another key underlying capability necessary to achieve future changes. The aviation industry is composed of many high-powered competing stakeholders, with strong incentives to support or oppose given changes. Anticipating and structuring the implementation of new system capabilities is key to managing potential stakeholder disputes.

Finally, safety approval processes present increasing challenges to introduction of new system capabilities. Better coordination is required during the early design process to evaluate system trades across distributed airborne and ground functionality and to adequately balance the requirements between current and future capabilities. Understanding is also needed of interactions and behavior in complex and software-intensive systems.

\section{REFERENCES}

[1] Joint Planning and Development Office, "Concept of operations for the next generation air transportation system," Jun. 13, 2007, JPDO Tech. Rep. ver. 2.0

[2] Joint Planning and Development Office, "Progress report to the next generation air transportation system integrated plan," Mar. 2006.

[3] U.S. Government Accountability Office, "Experts' views on improving the U.S. air traffic control modernization program," GAO-05-333SP, Apr. 13, 2005

[4] U.S. Government Accountability Office, "National Airspace System: Progress and ongoing challenges for the air traffic organization," GAO-05-485T, Apr. 14, 2005.

[5] A. Malwitz et al., "Assessment of the impact of reduced vertical separation on aircraft-related fuel burn and emissions for the domestic United States," Partnership for Air Transportation Noise and Emissions Reduction, Tech. Rep. PARTNER COE-2007-002, Nov. 2007.

[6] J. Q. Wilson, "The dead hand of regulation," Public Interest, vol. 25, p. 47, Fall, 1971.
[7] R. W. Cobb and C. D. Elder, Participation in American Politics: The Dynamics of Agenda Building, 2nd ed. Baltimore, MD: Johns Hopkins Univ. Press, 1983.

[8] J. Kingdon, Agendas, Alternatives, and Public Policies, 2nd ed. White Plains, NY: Longman, 2002.

[9] J. Frooman, "Stakeholder influence strategies," Acad. Manage. Rev., vol. 24, no. 2, pp. 191-205, Apr. 1999.

[10] R. K. Mitchell, B. R. Agle, and D. J. Wood, "Toward a theory of stakeholder identification and salience: Defining the principle of who and what really counts," Acad. Manage. Rev., vol. 22, no. 4, pp. 853-886, Oct. 1997.

[11] K. Marais and A. L. Weigel, "A framework to encourage successful technology transition in civil aviation," in Proc. 25th Digital Avion. Syst. Conf., 2006.

[12] A. Mozdzanowska et al., "System transition: Dynamics of change in the U.S. air transportation system," Ph.D. disseration, Massachusetts Inst. of Technology, Jun. 2008.

[13] E. Preston, FAA Historical Chronology: Civil Aviation and the Federal Government,
1926-1996. Washington, D.C.: U.S. Government Printing Office, 1998.

[14] FAA, "Air carrier operational approval and use of TCAS II," Advisory Circular 120-55, Oct. 1991.

[15] P. Bonnefoy et al., "Scalability of the air transportation system and development of multi-airport systems: A worldwide perspective," Ph.D. dissertation, Massachusetts Inst. of Technology, Cambridge, Jun. 2008.

[16] R. Watson et al., "Climate Change 2001: Synthesis report, summary for policymakers," Intergovernmental Panel on Climate Change, 2001.

[17] Federal Aviation Administration, "2007-2011 FAA Flight Plan," 2007.

[18] R. E. Kasperson, N. Jhaveri, and J. X. Kasperson, "Stigma and the social amplification of risk: Toward a framework of analysis," in Risk, Media and Stigma: Understanding Public Challenges to Science and Technology, J. Flynn, P. Slovic, and H. Kurnreuther, Eds. London, U.K. Earthscan, 2001, ch. 2, pp. 9-27. 
[19] Office of Aviation Policy and Plans, FAA, "Economic analysis of investment and regulatory decisions-Revised guide," FAA-APO-98-4, Jan. 1998.

[20] Department of Transportation, FAA, "Automatic Dependent SurveillanceBroadcast (ADS-B) Out performance requirements to support air traffic control (ATC) service," Notice of Proposed Rulemaking, Federal Register, vol. 72, no. 193, pp. 56 947-56 972, Oct. 5, 2007.

[21] RTCA, "Executive summary of the final report of RTCA Task Force 4, certification," Feb. 26, 1999.

[22] Federal Aviation Administration Safety Management System Manual, ver. 1.2, FAA Air Traffic Organization, 2004.

[23] Manual on Airspace Planning Methodology for the Determination of Separation Minima, International Civil Aviation Organization, Aug. 30, 2002, Doc. 9689, Amendment 1.

[24] NTSB, "Annual accident statistics show continued improvement in aviation safety," Press Release SB-07-13, Mar. 13, 2007.

[25] D. Jackson et al., Software for Dependable Systems, Sufficient Evidence? Washington, D.C.: National Academies, 2007.

[26] RTCA, "Software considerations in airborne systems and equipment certification," DO-178B, Dec. 1, 1992.

[27] RTCA, "Guidelines for approval of the provision and use of air traffic services supported by data communications," DO-264, Dec. 14, 2000.
[28] FAA, "Operational evolution partnership: Executive overview," Jun. 2007.

[29] Eurocontrol, "ADS-B Pre-SESAR implementation guidance," Cascade Tech. Doc., Aug. 31, 2007.

[30] Federal Aviation Administration. (2007. Apr. 13). Automatic Dependent Surveillance Broadcast (ADS-B). [Online]. Available: http:// www.faa.gov/airports_airtraffic/ technology/ads-b/

[31] FAA, "Draft regulatory impact analysis, draft regulatory flexibility analysis, international trade impact assessment, and unfunded mandates assessment," FAA-2007-29305-0004, Oct. 1, 2007.

[32] E. A. Lester and R. J. Hansman, "Benefits and incentives for ADS-B equipage in the National Airspace System," M.S. thesis, Massachusetts Inst. of Technology, Cambridge, Sep. 2007.

[33] RTCA, "Minimum operational performance standards for $1090 \mathrm{MHz}$ Automatic Dependent Surveillance-Broadcast (ADS-B) and Traffic Information Services (TIS-B)," DO-260, Sep. 13, 2000.

[34] G. Dunstone, "Consideration of existing ADS-B avionics, Australian Strategic Air Traffic Management Group, ADS-B implementation team," Rep. ABIT10-IP007 V2, 2007.

[35] FAA, "National Airspace System: System requirements specification," NAS SR-1000, Jan. 2005.

[36] RTCA, "Safety, performance and interoperability requirements document for the ADS-B non-radar-airspace (NRA) application," DO-303, Dec. 13, 2006.

[37] B. Tiemeyer, "The EUR RVSM pre-implementation safety case," Eurocontrol Rep. ver. 2.0, RVSM 691, Aug. 14, 2001.

[38] FAA, "Unmanned aircraft systems operations in the U.S. National Airspace System-Interim operational approval guidance," AFS-400 UAS Policy 05-01, Sep. 16, 2005.

[39] Dept. of Transportation, FAA, "Unmanned aircraft operations in the National Airspace System," Federal Register, Docket FAA-2006-25714, 2006.

[40] O. Sakamoto, "Industrial-use unmanned helicopter RMAX type II G," Yamaha Mot. Tech. Rev, pp. 122-125, 2003.

[41] Civil Aviation Safety Authority Australia, "Regulation impact statement, unmanned aircraft and rockets," RIS 0016, Mar. 14, 2001.

[42] M. DeGarmo and G. Nelson, "Prospective unmanned aerial vehicle operations in the future airspace system," presented at the AIAA 3rd Unmanned Unlimited Tech. Conf., Workshop Exhib., Sep. 20, 2004, AIAA-2004-6243.

[43] A. Zeitlin, J. Kuchar, and A. Drumm, Collision avoidance for unmanned aircraft: Proving the safety case, Lincoln Laboratory, Tech. Rep. 42PM ATC-329; MITRE Tech. Rep. MP060219, Oct. 2006.

\section{ABOUT THE AUTHORS}

Aleksandra L. Mozdzanowska received the bachelor's degree in aeronautics and astronautics and in literature from the Massachusetts Institute of Technology (MIT), Cambridge, in 2002, the master's degree from the MIT International Center for Air Transportation in 2004, and the Ph.D. degree from the Engineering Systems Division, MIT, in 2008.

Her thesis focused on the impact of regional jet growth on the national airspace system. Her

doctoral research focused on understanding transition dynamics in the air transportation system.

Roland E. Weibel received the bachelor's degree in aerospace engineering from the University of Kansas, Lawrence, in 2002 and the S.M. degree from the Massachusetts Institute of Technology (MIT), Cambridge, in 2005, where he is currently pursuing the Ph.D. degree in the Aeronautics and Astronautics Department.

His thesis focused on the integration of unmanned aerial vehicles into the National Airspace System. His doctoral research focuses on
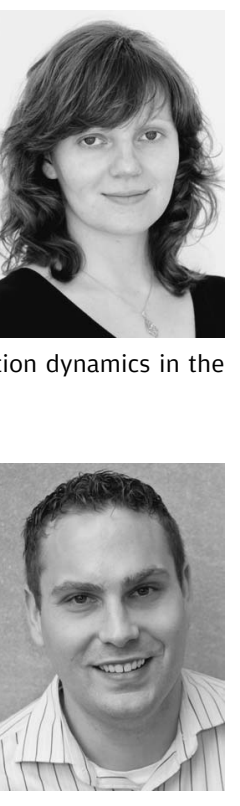

R. John Hansman (Member, IEEE) is a Professor of aeronautics and astronautics and engineering systems at the Massachusetts Institute of Technology (MIT), Cambridge, where he is the Director of the MIT International Center for Air Transportation. He conducts research in several areas related to the application of information technology in operational aerospace systems. He has received six patents and has authored more than 250 technical publications. He has more than

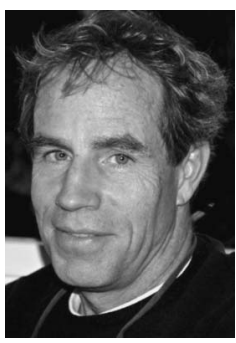
5300 hours of pilot in-command time in airplanes, helicopters, and sailplanes, including meteorological, production, and engineering flight test experience.

Prof. Hansman is a Fellow of the AIAA. 